Review Article

\title{
Vitamin D and Vitamin D Analogs as Adjuncts to Field Therapy Treatments for Actinic Keratoses: Current Research and Future Approaches
}

\author{
Zafer Sattouf $\mathbb{D}^{1},{ }^{1}$ Steven J. Repas $\mathbb{D}^{1},{ }^{1}$ Jeffrey B. Travers $\mathbb{D}^{1},{ }^{1,2,3}$ and Craig A. Rohan $\mathbb{D}^{1,2}$ \\ ${ }^{1}$ Department of Pharmacology and Toxicology, Wright State University, 3640 Colonel Glenn Hwy, Dayton, Ohio 45435, USA \\ ${ }^{2}$ Department of Dermatology, Wright State University, Dayton, Ohio 45435, USA \\ ${ }^{3}$ Dayton Veterans Administration Medical Center, Dayton, Ohio, USA
}

Correspondence should be addressed to Craig A. Rohan; craig.rohan@wright.edu

Received 9 March 2021; Accepted 11 June 2021; Published 19 June 2021

Academic Editor: Nihal Ahmad

Copyright (c) 2021 Zafer Sattouf et al. This is an open access article distributed under the Creative Commons Attribution License, which permits unrestricted use, distribution, and reproduction in any medium, provided the original work is properly cited.

Actinic keratoses (AK), also known as solar keratoses, are precancerous hyperkeratotic papules caused by long-term exposure to ultraviolet radiation. Management of AK prior to progression to cutaneous malignancy represents an important window of intervention. This is important on a population level, given the high incidence, morbidity, financial costs, and the low but measurable risk of mortality from cutaneous neoplasia. Treatments for AK have been refined for many years with significant progress over the past decade. Those recent advancements lead to questions about current treatment paradigms and the role of harnessing the immune system in field therapies. Recent studies suggest a key interplay between vitamin D and cancer immunity; in particular, the systemic and/or topical vitamin D analogs can augment field therapies used for severe actinic damage. In this review, we will examine the literature supporting the use of vitamin D-directed therapies to improve field therapy approaches. An enhanced understanding of these recent concepts with a focus on mechanisms is important in the optimized management of AK. These mechanisms will be critical in guiding whether selected populations, including those with immunosuppression, heritable cancer syndromes, and other risk factors for skin cancer, can benefit from these new concepts with vitamin $\mathrm{D}$ analogs and whether the approaches will be as effective in these populations as in immunocompetent patients.

\section{Introduction}

Actinic keratoses (AK) have the potential for malignant degeneration to squamous cell carcinoma (SCC), and that risk of malignant degeneration is increased in patients with a variety of susceptibility factors including immunosuppression, Fitzpatrick phototypes, and genetic factors $[1,2]$. While the AK lesions might be unsightly or minimally symptomatic, interventions are primarily intended to mitigate the risk of progression to in situ or invasive SCC [3]. Longstanding therapies have included physical modalities such as cryotherapy with liquid nitrogen, dermabrasion, chemical peels, or curettage [4]. Areas with numerous AK lesions are termed confluent AK or field cancerization. Treatments to these entire zones of skin, termed field therapies, are used to ameliorate the risk to the entire area of skin, including normal-appearing skin adjacent to the visible AK. Field therapy options include an array of topical therapies including 5-fluorouracil, fractional laser resurfacing, chemical peels, or topical photodynamic therapy (PDT) [5]. Though overall more effective than serially treating individual lesions, field therapies suffer from multiple side effects including pain and irritation. Moreover, the effects of field therapies such as topical PDT and even 5-fluorouracil only last several years [6]. Hence, there is a need in dermatooncology for adjunctive therapies that can improve the effectiveness of field therapies. As proposed in 2002 by van den Bemd, the use of vitamin D to treat skin cancers showed 
promise when used topically as monotherapy in 2009 by Seckin and colleagues $[7,8]$. The use of vitamin D agonists was further delineated in 2017 by Cunningham and colleagues with the expansion of the role of thymic stromal lymphopoietin (thymic stromal lymphopoietin role was first proposed by Demehri et al. in 2012) $[9,10]$. The goal of this review is to update new concepts in combining vitamin $\mathrm{D}$ agonists with field therapies for actinic damage.

\section{Vitamin D and Vitamin D Analogs}

Vitamin D is a vital prohormone that is obtained both from the diet and from production in epidermal keratinocytes via a reaction that requires ultraviolet (UV) radiation [11]. Vitamin D undergoes two hydroxylation reactions in the liver and then the kidneys to form the biologically active form 1,25-hydroxyvitamin D or calcitriol [12]. Vitamin D plays a key role in calcium-phosphorus homeostasis. Along with well-known effects on bone development, calcium likewise has many other effects on the immune system and the skin.

Completely independent of the calcium-mediated actions, significant additional research has also demonstrated many roles in the skin for vitamin D itself, including immune surveillance of cutaneous neoplasia along with regulation of cellular differentiation and proliferation $[13,14]$. Topical application of vitamin $\mathrm{D}$ analogs has been investigated as monotherapy for the treatment of field cancerization including actinic keratoses [8]. Topical vitamin D analogs have also been used as adjuncts to other field therapies, most prominently, with 5-fluorouracil [9].

Despite this emerging evidence on the role of systemic and topical vitamin D in ameliorating the risk of skin cancer, there are many remaining questions about vitamin D's optimal utility to decrease the longitudinal risk for skin cancer across multiple population groups (immunocompetent, immunocompromised, those with severe dermatoheliosis, and those with genetic, heritable conditions associated with increased malignancy risk). Notably, systemic vitamin D supplementation with oral or parenteral (Stoss therapy) formulations has not been investigated significantly as an adjunct to a number of current field therapy regimens.

\section{Vitamin D, AK, and Dermatoporosis}

While ultraviolet light is essential for the synthesis of vitamin $\mathrm{D}$ in the skin, it is also associated with nonmelanoma skin cancer (NMSC) development. Studies have shown that certain vitamin $\mathrm{D}$ receptor (VDR) polymorphisms are associated with a higher likelihood of developing AK [15]. These studies have encouraged many researchers to study vitamin $\mathrm{D}$ and its association with skin cancer; however, studies on this relationship have resulted in mixed and potentially inconsistent findings. Some studies have suggested that lower vitamin D levels increase the risk of skin cancer, while others have shown that increased levels can also increase the risk of skin cancer [16-18]. While vitamin D has a photoprotective effect on keratinocytes, studies have shown that this protection may be dose-dependent [19-21]. It is important to note that high doses of systemic vitamin D can be associated with hypercalcemic effects on the human body and although it has a wide therapeutic index, this fear has limited its use in clinical trials to further assess its systemic use as an anticancer agent. One cross-sectional study examined the status of vitamin $\mathrm{D}$ in patients with $\mathrm{AK}$ and demonstrated higher levels of serum $25(\mathrm{OH}) \mathrm{D}$ in patients with AK compared to healthy patients. This study suggested that while higher vitamin $\mathrm{D}$ levels correlate with higher numbers of $\mathrm{AK}$, it does not increase the risk itself [22].

Patients with severe sun damage (dermatoheliosis) have been hypothesized to suboptimally synthesize vitamin $\mathrm{D}$ in their sun-damaged skin. This is despite their significant sun exposure, including at the wavelengths needed to produce vitamin $\mathrm{D}$ in the skin. This phenomenon has been termed "dermatoporosis" and a correlation between dermatoporosis and osteoporosis from insufficient skin production of vitamin $\mathrm{D}$ has been made [23]. This raises a number of key questions. First, whether systemic or topical vitamin D options have equivalent ability to modify the risk of neoplasia. Second, whether vitamin D's effectiveness as an adjuvant to field therapies is achieved by restoring vitamin D levels in areas of sun-damaged skin that are functionally deficient or is the effectiveness dependent on locally supratherapeutic amounts of vitamin D achieved through local, topical application of the vitamin $\mathrm{D}$ analogs. Another potentially important area is the discovery of novel noncalcemic vitamin $\mathrm{D}$ analogs which could be used in this area [13].

\section{Vitamin D Mechanism of Action}

Calcitriol and other agonists mediate their effects by interacting with the vitamin $\mathrm{D}$ receptor (VDR). Binding with VDR promotes heterodimerization with the retinoid $\mathrm{X}$ receptor, leading to translocation of this complex into the nucleus where it regulates the transcription of target genes $[14,24-27]$. It is interesting that vitamin $\mathrm{D}$ is both produced in the skin and exerts its effects on the skin via VDR. VDR transcription rate depends on the availability of VDR agonists and antagonists and can also be influenced by singlenucleotide polymorphisms, which play a role in the etiology of NMSC [28-33]. In the skin, VDR expression can fluctuate based on the pathology of skin conditions. For instance, a knockout VDR mouse model showed an increased risk of developing skin cancer, which suggests VDR potentially functioning as a tumor suppressor [34].

In addition to its genomic activity, the VDR can additionally cause a rapid response via nongenomic, membranebound mechanisms, in which VDR is associated with flaskshaped invaginations in the cellular plasma membrane, called caveolae [27]. VDR studies have shown that calcitriol has a similar binding affinity to this plasma membranebound VDR relative to that seen with nuclear VDR. The activation of this membrane-bound, caveolae-associated VDR activates numerous rapid signal transduction pathways and second messenger systems, including phospholipase $\mathrm{C}$ and phospholipase $A_{2}, G$ protein-coupled receptors, 
phophatidylinositol-3'-kinase (PI3K), or protein kinase C. This nongenomic activity also leads to opening of calcium and chloride channels in the cell membrane [35]. The downstream effect of this membrane-bound receptor activation facilitates crosstalk inside the cell, eventually leading to changes in gene expression similar to those seen with the genomic response of VDR [27]. In fact, in vivo studies by Dixon et al. reported for the first time that this rapid-response pathway of membrane-bound VDR can indeed have photoprotective effects on UVR-induced sunburn cells [36].

In vitro studies have indicated that calcitriol exerts both antiproliferation and prodifferentiation roles on keratinocytes in a VDR-dependent manner [37]. The antiproliferation effect is mediated by inhibition of G1/S checkpoint enzymes, upregulation of inhibitors of CDKs, inhibition of cyclin D1, and upregulation of p27 and p21 [38-40]. Indirect mechanisms of $1,25(\mathrm{OH})_{2} \mathrm{D}_{3}$ antiproliferation effects also include upregulation of TGF- $\beta$ and downregulation of EGFR found in normal keratinocytes [41-43]. As for the prodifferentiation effects, 1 , $25(\mathrm{OH})_{2} \mathrm{D}_{3}$ has been shown to play an important role in the differentiation of keratinocytes from epidermal precursor cells, as well as macrophage differentiation from myelopoietic progenitor cells $[37,44]$. In addition, mutations of proteins involved in both the synthesis and the catabolism of vitamin D were found to be of importance in many cancers, including SCC [45]. Additional studies on mice have reported that VDR knockout mice exposed to oral 7, 12-dimethylbenzanthracene (DMBA) had increased sensitivity to develop chemically induced skin tumors [46]. These findings, among many others, suggest an important role for vitamin D in skin cancer pathogenesis and treatment [47].

In addition to the antiproliferative and prodifferentiative effects of calcitriol on cells, calcitriol has a number of immunological effects. Calcitriol plays a role in innate immunity via increasing the expression of the human antimicrobial peptides cathelicidin and defensin $\beta_{2}$. This increase in cathelicidin levels causes a more intense activity of phagocytic macrophages in lesional skin, such as those found in psoriasis [48-50].

\section{Vitamin D Immunomodulatory Action}

When applied topically on epithelial cells, calcitriol and its analogs have been shown to induce the expression of the cytokine thymic stromal lymphopoietin (TSLP) [51]. TSLP and IL-7 are both cytokines that are similar in their structures [52]. The receptors for TSLP and IL-7 can together form a heterodimer that is expressed on $\mathrm{CD} 11 \mathrm{c}+$ dendritic cells [52]. TSLP binding to this receptor can induce thymus and activation-related chemokine (TARC, also known as CCL17) and macrophage-derived chemokine (MDC, also known as CCL22), resulting in a Th2-enriched inflammation [52-54]. In addition, TSLP inhibits Th1 and Th17 differentiation, which has been suggested to be associated with the reduction of psoriatic plaques [55]. A study by Sato-Deguchi and colleagues reported that vitamin D analogs induce TSLP and cathelicidin, both of which result in the suppression of IL-12/23 p 40 , IL- $\alpha$, IL- $1 \beta$, and TNF- $\alpha$, thereby improving psoriatic plaques [55].
The immunomodulatory roles of TSLP in inflammation and cancer pathogenesis mentioned previously have become an interest for many researchers and pharmaceutical companies. Several studies have reported that TSLP can promote neoplastic growth of breast and pancreatic tissues in animal models [56-58]. Alternatively, TSLP actions have demonstrated a protective role in the carcinogenesis of skin neoplasms [59]. The study by Piazza et al. showed that this protective role was mediated by the direct signaling of TSLP on CD4+ and CD8+ T-cells that reside in the skin, resulting in an inflammatory response that can inhibit cancer development [59]. On a molecular level, activation of T-cells by TSLP was shown to inhibit the growth of $\beta$-catenin-dependent skin tumors. Furthermore, removing this TSLP-mediated response was shown to significantly change the inflammatory response and promote neoplastic growth in the skin [59].

The findings of an antitumoral effect of TSLP in the skin are further supported by Demehri and colleagues [9]. They found that TSLP upregulation in the skin mediated a lasting tumor rejection reaction via CD4+ T-cell response in a Th2 inflammatory pathway. This finding suggests that this antitumor response protects the skin from UV-and chemically induced neoplasms. CD4+ T-cells that were responsive to TSLP action were found to be both required and sufficient to mediate these preclinical effects of TSLP. It was also found that TSLP overexpression in the skin resulted in tumorigenesis resistance, thus confirming the tumor-suppressive effects of TSLP in the skin.

Cunningham et al. examined the efficacy of topical TSLP induction via calcipotriol in preventing skin cancer development in murine skin that was chemically treated with DMBA and tetradecanoylphorbol-13-acetate (TPA) [10, 60]. They found that calcipotriol application to the skin induced TSLP expression and resulted in a delay in developing skin cancer compared to no treatment. It was also found that calcipotriol did not have this cancer-protective effect in animal models lacking the TSLP receptor, thus clearly demonstrating the importance of TSLP in mediating this cancer immunity effect of vitamin D analogs. Even short pulses of calcipotriol application on DMBA-TPA-treated skin resulted in a transient increase in TSLP levels and exerted a long-lasting antitumor effect [10].

This TSLP upregulation of T-cell function may have implications in how vitamin D functions in immunocompromised patients (including organ transplant recipients at high risk of morbidity and mortality from NMSC) and patients with heritable, genetic cancer syndromes including those with altered DNA mismatch repair capability. One study investigated the use of topical calcipotriol cream as monotherapy or in combination with all-trans retinoic acid cream in renal transplant patients with actinic keratosis [61]. This study found that neither treatment was effective in treating actinic keratosis; however, these results cannot be generalized to the immunocompetent population. A study by Seckin et al. on immunocompetent patients with $\mathrm{AK}$ treated with calcipotriol as monotherapy has shown supportive results for the efficacious use of this treatment [8]. However, the absence of inflammation at treatment sites and the small number of participants in this study make the statistical significance unreliable. 


\section{Vitamin D plus 5-FU Combination Treatment for Actinic Keratosis}

The promising findings of Seckin et al. prompted the use of $0.005 \%$ calcipotriol in combination with 5\% 5-FU for 4 days versus vaseline for 4 days in a randomized, double-blinded clinical trial on human patients as field therapy for AK [10]. This study by Cunningham and colleagues demonstrated that this combination treatment resulted in the accumulation of lymphocytes at the sites of AK. The erythema at the site of treatment was found to be associated with various immunological reactions, including lymphocyte exocytosis, epidermal spongiosis, and dyskeratosis, resulting in tumor rejection in the skin. The majority of these lymphocytes were CD4+ T-cells, further emphasizing the antitumor role of TSLP found by Demehri et al. [9]. The inflammatory reactions seen in the combination treatment showed a significant lesional epidermis rejection pattern that was specific to the actinically damaged sites, without involving the adjacent normal tissue. It is suggested that the TSLP, HLA class II, and cellular stress signals from the cytotoxic effects of chemotherapy with 5-FU interact synergistically to mediate the immunotherapeutic effects of this combination treatment.

When comparing the combination treatment versus 5$\mathrm{FU}$ alone, it is suggested that the natural killer group 2D (NKG2D) synergizes with TSLP in the combination treatment and causes suppression of cancer development [10]. This synergistic reaction does not occur when using 5-FU alone. The findings by Cunningham et al. indicated for the first time the efficacy of combination treatment of 5-FU plus calcipotriol in AK treatment. It was shown that a twice daily, 4-day application of 5-FU plus calcipotriol caused a mean reduction of $87.8 \%$ in the number of AK on the face, while 5FU plus vaseline caused a mean reduction of $26.3 \%$. The superior efficacy of this combination treatment was evident on other anatomical sites, including the scalp and upper extremities (see Table 1) [10]. These findings further emphasize the role of CD4+ T-cells in mediating antitumor immunity via TSLP induction. However, it is important to note that the applicability of these findings is limited to patients with competent immune systems and cannot be generalized as yet to all patients with $\mathrm{AK}$.

The efficacy of 5-FU plus calcipotriol combination treatment is further highlighted by the decreased side effects seen in the treatment group in the trial using such shortterm exposures. This is in contrast to side effects seen in 5FU monotherapy for actinic keratosis which typically use much longer treatment times [62]. In addition, this combination treatment appears superior to imiquimod monotherapy as the latter only activates the innate immune system and lacks the antigen specificity provided by the HLA class II and MICB expression seen in lesional keratinocytes treated with 5-FU plus calcipotriol. This latter finding is of great importance because of the role of HLA class II and MICB in their presentation of tumor antigens. However, future studies comparing combination therapies to current monotherapy field therapy options are needed.

\section{Vitamin D and Skin Cancer Prevention}

One of the limitations of the study by Cunningham et al. [10] was focusing on the elimination of AK with the combination treatment without studying the long-term potential of preventing skin cancer development. In fact, this limitation is shared by many of the currently used treatments for AK, including photodynamic therapy, cryosurgery, imiquimod, diclofenac, and ingenol mebutate. The only currently used topical treatment that has shown a potential to prevent skin cancer in the long term was 5-FU. However, even this benefit of 5-FU treatment was limited to 2 years after treatment [63].

The long-term protection from skin cancer development in patients with $\mathrm{AK}$ treated with the combination of 5-FU plus calcitriol was investigated in a randomized clinical trial by Rosenberg et al. [55]. Evidence of epidermal CD4+ and CD8+ tissue-resident memory T-cells and adaptive immune response activation were found in skin treated with this combination, further confirming previous results. The majority of these cells were CD69+ and CD103+, confirming their tissue-resident memory $\mathrm{T}$-cell status. In contrast to the findings of 1-year skin cancer protection by 5-FU monotherapy, the study by Rosenberg et al. found that the 4-day course of calcipotriol plus 5-FU immunotherapy was successful in preventing SCC development on the face and scalp up to 3 years following treatment $[63,64]$. Eliminating precancerous lesions and yielding long-term cancer prevention potential via immunotherapeutic agents is a novel concept that has broad implications in the treatment and prevention of skin cancer and possibly even solid tumors.

\section{Vitamin D with Other Topicals for Field Therapies and PDT}

With other pharmaceuticals used to treat AK/SCC producing a significant side effect profile, the use of more combination therapies is being tested [65], one of which is the combination of topical vitamin $\mathrm{D}$ analogs with several FDA-approved topicals. These combinations include vitamin $\mathrm{D}$ with photodynamic therapy, imiquimod, ingenol mebutate, and diclofenac sodium (see Tables 2 and 3).

8.1. Imiquimod. Imiquimod is an immunomodulatory agent commonly used in the treatment of viral and nonviral illnesses [66]. While the mechanism of action is not definitively known, it is believed to bind to toll-like receptor 7 (TLR-7). This binding activates a directed innate immune response via IFN- $\alpha$, TNF- $\alpha$, IL-12, and other proinflammatory cytokines directed against intracellular pathogens and tumors [67]. In addition to 
TABLE 1: Summary of results of the clinical trial of 5-FU plus calcipotriol versus 5-FU plus vaseline [10].

\begin{tabular}{|c|c|c|c|}
\hline & & 5-FU plus calcipotriol (\%) & 5-FU plus vaseline (\%) \\
\hline \multirow{4}{*}{ Mean reduction in the number of actinic keratoses } & Face & 87.8 & 26.3 \\
\hline & Scalp & 76.4 & 5.7 \\
\hline & RUE & 68.8 & 9.6 \\
\hline & LUE & 76 & 16.3 \\
\hline Complete clearance of AK on the face & & 27 & 0 \\
\hline \multirow{4}{*}{ Partial clearance of $\mathrm{AK}$} & Face & 80 & 0 \\
\hline & Scalp & 56 & 0 \\
\hline & RUE & 30 & 4 \\
\hline & LUE & 56 & 3 \\
\hline \multirow{4}{*}{$\begin{array}{l}\% \text { of participants who had reduction of AK counts on all treated anatomical } \\
\text { sites }\end{array}$} & Face & 100 & 80 \\
\hline & Scalp & 100 & 71 \\
\hline & RUE & 100 & 65 \\
\hline & LUE & 100 & 77 \\
\hline
\end{tabular}

RUE: right upper extremity; LUE: left upper extremity.

acute innate immune response induction, imiquimod also influences memory $\mathrm{T}$-cells and humoral immunity that creates a sustained effect on viral pathogens and tumors until they are fully eradicated [68]. The use of imiquimod against AK has been well documented as efficacious [69]. The immunomodulatory effect of imiquimod is highly effective at decreasing the amount of $\mathrm{AK}$ in patients with very limited amounts of recurrence $[70,71]$. Significant side effects are common, which limit the frequency and concentration of dosing [72]. There have also been questions about the variability of expression of TLR7 between patients as some patients have a minimal clinical response to treatment courses.

Imiquimod has been used in conjunction with PDT in several clinical trials. Those treated with the combination showed higher rates of complete and partial clearance of AK [73]. These findings provide support for the concept that dual field therapies could be more efficacious than individual therapies. Moreover, although not reported in the literature, a trial combining a vitamin D analog, like calcipotriol, with imiquimod to see if a similar synergy is elucidated would be of significant interest.

8.2. Ingenol Mebutate. Ingenol mebutate has complex and incompletely understood dual mechanisms [82]. Although recent label changes and safety concerns by both the European Medicines Agency (EMA) and the US FDA have raised concerns about the long-term safety of this medicine, it remains one of the field therapies that may show enhancement with a vitamin D adjunct [83]. Ingenol mebutate causes mitochondrial membrane instability and subsequent apoptosis of tumor cells. This first mechanism shows an effect within hours of application. The exact mechanism causing this instability is unknown [84]. The second mechanism involves recruitment of neutrophils to the apoptotic cells, which mediates antibody-dependent cellular cytotoxicity [85]. This is a delayed response and involves reactive oxygen species released from neutrophils. Ingenol mebutate has been shown to successfully treat $\mathrm{AK}$ and prevent the progression to SCC $[86,87]$. It is also well documented to have a superior tolerability profile when compared to other topicals used to treat AK $[88,89]$.
Similar to imiquimod, ingenol mebutate has been used in combination with PDT in several clinical trials [90]. These studies concluded that the combined effect of PDT and ingenol mebutate was superior to these therapies individually, indicating a potential synergistic effect [91]. Patients also reported high satisfaction and tolerability with the combinatory therapy [92]. These promising findings warrant further clinical studies and new combinations. Currently, there are no published studies showing the effects of ingenol mebutate when paired with vitamin D analogs.

8.3. Diclofenac Sodium. Diclofenac sodium is a member of the nonsteroidal anti-inflammatory drug family [93]. Diclofenac sodium is a nonselective competitive inhibitor of cyclooxygenases (COX-1 and COX-2) within the prostaglandin synthesis pathway [94]. AK and SCC have been shown to have upregulated COX-2 expression with subsequent prostaglandin $\mathrm{E}_{2}$ accumulation [95]. Downregulation of COX-2 byproducts may explain the beneficial use of topical diclofenac sodium in treating both AK and SCC [96]. Further studies have indicated a potential induction of apoptosis within precancerous and cancerous cells as a proposed mechanism of diclofenac sodium [97]. Other mechanisms for the anticarcinogenic effects of COX inhibition could include augmenting antitumoral immunity. Clinically, topical diclofenac sodium is one of the most easily tolerated field treatments for AK $[98,99]$.

The majority of studies that combine the effects of diclofenac and vitamin $\mathrm{D}$ are documented in mice. It has been found that there is a significant reduction in tumor load and overall tumor prevention in mice with the synergistic effects of calcipotriol and diclofenac sodium [100]. Other preclinical studies have reported the superiority of this combination versus placebo in decreasing tumor size [101]. While these animal studies show a great deal of potential, there are a number of gaps within the literature [100]. First, there are no published human studies of this combination against AK/SCC to show side effect profiles, safety profiles, and efficacy [102]. Further, the exact mechanism of the synergy seen in these animal studies has yet to be elucidated and warrants further investigation. 
TABle 2: Comparison between current treatments of AK.

Clinical trial/studies

5\% 5-FU + glycolic acid (GA) vs. GA alone [74]

\% 5-FU vs. $30 \%$ trichloroacetic acid peel vs. $\mathrm{CO}_{2}$ laser resurfacing [75]

5\% 5-FU vs. $\mathrm{CO}_{2}$ laser resurfacing (LA) [76]

5\% 5-FU vs. cryotherapy vs. imiquimod [77]

5\% 5-FU vs. imiquimod [78]

$0.5 \%$ 5-FU vs. placebo [79] Primary outcomes/findings

(1) Combination treatment cleared $92 \%$ of AK on the face at 6 months vs. $20 \%$ with GA alone

(1) $83 \%$ to $92 \%$ AK reduction in treatment groups vs. control (no treatment)

(2) Lower incidence of NMSC in comparison with control

(3) No significant difference in reduction of AK or NMSC protection among the treatment groups

(4) Limited by small participants number

(1) $\mathrm{CO}_{2}$ laser resurfacing resulted in less $\mathrm{AK}$ recurrence

(2) Recurrence rates for LA were $21.7 \%, 21.7 \%$, and $25.9 \%$ at 3, 6, and 12 months after treatment

(3) Recurrence rates for FU were $61.5 \%, 57.7 \%$, and $60.0 \%$ at 3, 6, and 12 months after treatment

(4) Side effects more frequent in the laser resurfacing group, especially

hypopigmentation and erythema

(1) Total clearance rates of AK were $68 \%$ for cryotherapy, $85 \%$ for imiquimod, and $96 \%$ for $\mathrm{FU}$

(2) Higher rates of recurrence at 12 months seen in the FU and cryotherapy-treated group

(3) Imiquimod was judged to have the best cosmetic outcomes

(1) 5-FU was more effective than imiquimod in exposing subclinical AK, reducing $\mathrm{AK}$ counts at 24 weeks ( $94 \%$ vs. $66 \%$ ), achieving complete clearance at 24 weeks ( $84 \%$ vs. $24 \%)$

(2) Erythema as a side effect was higher in the 5-FU arm

(1) Mean AK count reduction at 4 weeks was $62.4 \%$ in the 5 -FU group vs. $28.8 \%$ in the vehicle group

(2) Complete clearance was $16.7 \%$ with $\mathrm{FU}$ and $0 \%$ in the vehicle group

(1) 5 -FU was as equivalent to blue-PDT in achieving $>75 \%$ AK clearance

(2) Cumulative clearance rate at 4 weeks after treatment for 5-FU, blue-PDT, and

PDL-PDT was $79 \%, 80 \%$, and $50 \%$, respectively

(3) PDT using ALA plus laser light was the least effective among the treatment arms

(4) Both PDT treatment arms had lower side effect profile than 5-FU

(1) At 6 months after treatment, fewer AK were found in 5-FU treated patients compared

to control (no treatment)

Long-term efficacy of 5\% 5-FU [81]

(2) Higher complete AK clearance in $5-\mathrm{FU}$ vs. control (38\% vs. $17 \%$ at 6 months)

(3) Fewer spot treatments at 6-month intervals and in between study visits were reported in the 5-FU treated patients

(4) No difference in the number of hypertrophic AK between the two groups

(1) At 1 year after treatment, a $75 \%$ risk reduction of developing squamous cell carcinoma was seen in patients treated with 5 -FU vs. vehicle cream

(2) No significant effect was seen in the development of basal cell carcinoma

$5 \%$ 5-FU prevention of skin cancer [63]

focused light interacts with the protoporphyrin IX creating reactive oxygen species (ROS) within cells; these induce apoptosis in a very precise area of the skin $[109,110]$. PDT has been well documented in its efficacy and safety profile in treating AK and SCC alike with AK clearance one year after treatment up to $47 \%[111,112]$. PDT use in AK/SCC treatment is generally well tolerated by patients [113].

The concomitant use of PDT with calcipotriol and other vitamin D analogs has been examined [73, 114-116]. Preclinical studies using murine BCC and SCC demonstrated the synergistic effects of vitamin D agonists to "precondition" the tumors before PDT [114-116]. These important preclinical studies have not as yet been fully translated into human studies. However, the addition of topical calcipotriol has been shown to significantly improve AK clearance [117] compared to MAL or 5-ALA alone [118]. Patients also inmune response [107]. Next, a very specific wavelength of light is focused on target areas with confluent AK [108]. The 
TABLE 3: Brief meta-analysis of FDA-approved topical therapies combined with topical vitamin D analogs in the treatment of AK.

\begin{tabular}{|c|c|c|}
\hline Compound & Study & Primary outcomes/findings \\
\hline Imiquimod & $\begin{array}{l}\text { (1) Bhatta et al. [102] } \\
\text { (2) Baneerjee et al. [69] } \\
\text { (3) Befon et al. [123] }\end{array}$ & $\begin{array}{l}\text { (1) Enhanced efficacy against invasive squamous cell carcinoma } \\
\text { (2) Increased clearance rate of actinic keratoses and change in lesion count } \\
\text { (3) Effectively cleared both clinical and subclinical actinic keratoses }\end{array}$ \\
\hline Ingenol mebutate & $\begin{array}{l}\text { (1) Rosen et al. [82] } \\
\text { (2) Gras [124] } \\
\text { (3) Anderson et al. [125] }\end{array}$ & $\begin{array}{l}\text { (1) Treatment for only 2-3 days resulting in rapid lesion necrosis of actinic } \\
\text { keratoses } \\
\text { (2) Significant reduction of head and nonhead actinic keratoses in a short } \\
\text { duration of treatment } \\
\text { (3) Significant complete clearance rate and partial clearance rate in nonfacial } \\
\text { actinic keratoses }\end{array}$ \\
\hline Diclofenac sodium & $\begin{array}{l}\text { (1) Pommergaard et al. [100] } \\
\text { (2) Ulrich et al. [95] } \\
\text { (3) Martin et al. [98] }\end{array}$ & $\begin{array}{l}\text { (1) Significant reduction of tumor size } \\
\text { (2) Significant field cancerization treatment of actinic keratoses } \\
\text { (3) Significant long-term clearance of actinic keratoses }\end{array}$ \\
\hline $\begin{array}{l}\text { Photodynamic } \\
\text { therapy }\end{array}$ & $\begin{array}{l}\text { (1) Fu et al. [111] } \\
\text { (2) Neittaanmaki-Perttu et al. } \\
\text { [126] } \\
\text { (3) Heppt et al. [73] }\end{array}$ & $\begin{array}{l}\text { (1) Significant increased complete clearance rate of grade II-III actinic keratoses } \\
\text { lesions } \\
\text { (2) Complete histological clearance with increased patient preference due to low } \\
\text { adverse effects } \\
\text { (3) Increased clearance rates compared to monotherapy alone }\end{array}$ \\
\hline
\end{tabular}

tolerated PDT with vitamin D analogs well [119]. Mechanistic studies suggest that the addition of calcipotriol increases coproporphyrinogen oxidase, a heme breakdown enzyme, which creates additional ROS within cancerous cells, increasing apoptosis in these cells [120].

\section{Future Recommendations}

There are several therapeutic questions remaining. These include the efficacy and tolerability of vitamin $\mathrm{D}$ analogs to treat $\mathrm{AK}$ on extremities and nonfacial skin. While 5-FU plus calcipotriol combination treatment showed $\mathrm{AK}$ reduction and SCC protection on the face and scalp, no similar significant differences were noted for field therapy treatments on the extremities. This limitation can be addressed by future studies using the same treatment but potentially for a longer period of time, enough to induce a higher degree of erythema and adaptive immune response via T-cell activation in AK lesions. In addition, 5-FU plus calcipotriol showed no potential benefit in preventing BCC, further supporting the immune-based mechanism of this therapy [64]. Mutations in AK and SCC are similar in their nature of antigen presentation, whereas BCC mutations involve the hedgehog signaling pathway [121].

A second therapeutic gap is designing treatments, which would be effective in high-risk populations, especially those with compromised immune systems. It is important to note that combination therapy of 5-FU with calcipotriol appears dependent on the adaptive immune response and infiltration of T-cells in immunocompetent patients. This important finding can theoretically limit the use of this novel treatment in immunocompromised and organ transplant patients. MAL-PDT, cryotherapy, and 5-FU are currently the treatments of choice for AK in transplant patients [122]. A clinical trial of calcipotriene monotherapy, all-trans retinoic acid monotherapy, or a combination of both has been previously studied in renal transplant patients. Unfortunately, none of these treatments had a marked reduction in the number of AK lesions [61]. However, with 5-FU as one of the standard treatments for transplant patients with $\mathrm{AK}$, the novel 5-FU plus calcipotriol combination might potentially be of higher benefit to these patients. Future research is especially important for these immunocompromised patients and other high-risk patients, whose risk of progression to SCC and the subsequent risk of more serious complications of SCC is increased. This population may require combination treatments that are less reliant on the patient's own immune system, for example, fractional laser resurfacing, photodynamic therapy with aminolevulinic acid, or chemical peels.

A final knowledge and therapeutic gap concerns the use of topical vs systemic vitamin D analogs in combinatorial therapy. A potential advantage of oral or injected (Stoss) vitamin D is its low cost. Future studies could help identify whether subsequent systemic repletion, independent of any comorbid vitamin D deficiency, could decrease the risk for actinic neoplasia.

\section{Abbreviations}

AK: $\quad$ Actinic keratosis

SCC: Squamous cell carcinoma

NMSC: Nonmelanoma skin cancer

VDR: Vitamin D receptor

TSLP: Thymic stromal lymphopoietin

COX: Cyclooxygenase

5-FU: 5-Fluorouracil

PDT: Photodynamic therapy

TLR-7: $\quad$ Toll-like receptor 7

DMBA: 7,12-Dimethylbenzanthracene

NKG2D: Natural killer group 2D.

\section{Conflicts of Interest}

The authors declare no conflicts of interest. 


\section{Authors' Contributions}

Zafer Sattouf and Steven J. Repas contributed equally to this work.

\section{Acknowledgments}

The authors acknowledge the support from the National Institutes of Health (1R01ES031087 to J. B. T. and C. A. R) and US Veterans Administration (1101CX000809 and 510BX000853 to J. B. T.).

\section{References}

[1] V. Ratushny, M. D. Gober, R. Hick, T. W. Ridky, and J. T. Seykora, "From keratinocyte to cancer: the pathogenesis and modeling of cutaneous squamous cell carcinoma," Journal of Clinical Investigation, vol. 122, no. 2, pp. 464-472, 2012.

[2] D. Czarnecki, C. J. Meehan, F. Bruce, and G. Culjak, "The majority of cutaneous squamous cell carcinomas arise in actinic keratoses," Journal of Cutaneous Medicine and Surgery, vol. 6, no. 3, pp. 207-209, 2002.

[3] S. Guenthner, R. M. Hurwitz, L. J. Buckel, and H. R. Gray, "Cutaneous squamous cell carcinomasconsistently show histologic evidence of in situchanges: a clinicopathologic correlation," Journal of the American Academy of Dermatology, vol. 41, pp. 443-448, 1999.

[4] N. Jetter, N. Chandan, S. Wang, and M. Tsoukas, "Field cancerization therapies for management of actinic keratosis: a narrative review," American Journal of Clinical Dermatology, vol. 19, no. 4, 2018.

[5] E. Campione, A. Ventura, L. Diluvio et al., "Current developments in pharmacotherapy for actinic keratosis," Expert Opinion on Pharmacotherapy, vol. 19, no. 15, pp. 1693-1704, 2018.

[6] T. Rosen, M. G. Lebwohl, and P. Zografos, "Prevalence and awareness of actinic keratosis: barriers and opportunities," Journal of the American Academy of Dermatology, vol. 68, no. 1, p. S2, 2013.

[7] G. van den Bemd and G. T. G. Chang, "Vitamin D and vitamin D analogs in cancer treatment," Current Drug Targets, vol. 3, no. 1, 2002.

[8] D. Seckin, A. A. Cerman, A. Yildiz, and T. Ergun, "Can topical calcipotriol be a treatment alternative in actinic keratoses? a preliminary report," Journal of Drugs in Dermatology, vol. 8, no. 5, pp. 451-454, 2009, https://www. researchgate.net/publication/26302261.

[9] S. Demehri, A. Turkoz, S. Manivasagam, L. J. Yockey, M. Turkoz, and R. Kopan, "Elevated epidermal thymic stromal lymphopoietin levels establish an antitumor environment in the skin," Cancer Cell, vol. 22, no. 4, pp. 494-505, 2012.

[10] T. J. Cunningham, M. Tabacchi, J. P. Eliane et al., "Randomized trial of calcipotriol combined with 5-fluorouracil for skin cancer precursor immunotherapy," Journal of Clinical Investigation, vol. 127, no. 1, pp. 106-116, 2017.

[11] J. Y. Tang, T. Fu, C. Lau, D. H. Oh, D. D. Bikle, and M. M. Asgari, "Vitamin D in cutaneous carcinogenesis: part II," Journal of the American Academy of Dermatology, vol. 67, no. 5, pp. 817.e1-817.e11, 2012.

[12] H. F. DeLuca, "Overview of general physiologic features and functions of vitamin D," The American Journal of Clinical Nutrition, vol. 80, pp. 1689S-1696S, 2004.
[13] A. T. Slominski, A. A. Brożyna, M. A. Zmijewski et al., "The role of classical and novel forms of vitamin D in the pathogenesis and progression of nonmelanoma skin cancers," Advances in Experimental Medicine and Biology, vol. 1268, pp. 257-283, 2020.

[14] R. C. Tuckey, C. Y. S. Cheng, and A. T. Slominski, "The serum vitamin $\mathrm{D}$ metabolome: what we know and what is still to discover," Journal of Steroid Biochemistry and Molecular Biology, vol. 186, pp. 4-21, 2019.

[15] M. A. Carless, T. Kraska, N. Lintell, R. E. Neale, A. C. Green, and L. R. Griffiths, "Polymorphisms of the VDR gene are associated with presence of solar keratoses on the skin," British Journal of Dermatology, vol. 159, no. 4, pp. 804-810, 2008.

[16] J. Y. Tang, N. Parimi, A. Wu et al., "Inverse association between serum $25(\mathrm{OH})$ vitamin D levels and non-melanoma skin cancer in elderly men," Cancer Causes and Control, vol. 21, no. 3, pp. 387-391, 2010.

[17] M. J. Eide, D. A. Johnson, G. R. Jacobsen et al., "Vitamin D and nonmelanoma skin cancer in a health maintenance organization cohort," Archives of Dermatology, vol. 147, no. 12, pp. 1379-1384, 2011.

[18] J. Y. Tang, T. Fu, E. LeBlanc et al., "Calcium plus vitamin D supplementation and the risk of nonmelanoma and melanoma skin cancer: post hoc analyses of the women's health initiative randomized controlled trial," Journal of Clinical Oncology, vol. 29, no. 22, pp. 3078-3084, 2011.

[19] P. de Haes, M. Garmyn, H. Degreef, K. Vantieghem, R. Bouillon, and S. Segaert, "1,25-Dihydroxyvitamin D3 inhibits ultraviolet B-induced apoptosis, Jun kinase activation, and interleukin- 6 production in primary human keratinocytes," Journal of Cellular Biochemistry, vol. 89, no. 4, pp. 663-673, 2003.

[20] K. Hanada, D. Sawamura, H. Nakano, and I. Hashimoto, "Possible role of 1,25dihydroxyvitamin D,-induced metallothionein in photoprotection against UVB injury in mouse skin and cultured rat keratinocytes," Journal of Dermatological Science, vol. 9, pp. 203-208, 1995.

[21] J.-H. Lee and J. Youn, "The photoprotective effect of 1,25dihydroxyvitamin $\mathrm{D}_{3}$ on ultraviolet light $\mathrm{B}$-induced damage in keratinocyte and its mechanism of action," Journal of Dermatological Science, vol. 18, pp. 11-18, 1998.

[22] A. Aksu Çerman, E. Aktaş Karabay, I. K. Altunay, and S. Küçükoğlu Cesur, "Vitamin D levels in actinic keratosis: a preliminary study," Anais Brasileiros de Dermatologia, vol. 93, no. 4, pp. 535-538, 2018.

[23] G. Kaya, A. Kaya, O. Sorg, and J. H. Saurat, "Dermatoporosis, a prevalent skin condition affecting the elderly: current situation and potential treatments," Clinics in Dermatology, vol. 37, no. 4, pp. 346-350, 2019.

[24] R. Bouillon, C. Marcocci, G. Carmeliet et al., "Skeletal and extraskeletal actions of vitamin D: current evidence and outstanding questions," Endocrine Reviews, vol. 40, no. 4, pp. 1109-1151, 2019.

[25] C. Carlberg, "Vitamin D genomics: from in vitro to in vivo," Frontiers in Endocrinology, vol. 9, 2018.

[26] S. Christakos, S. Li, J. de La Cruz, and D. D. Bikle, "New developments in our understanding of vitamin metabolism, action and treatment," Metabolism: Clinical and Experimental, vol. 98, pp. 112-120, 2019.

[27] M. R. Haussler, P. W. Jurutka, M. Mizwicki, and A. W. Norman, "Vitamin D receptor (VDR)-mediated actions of $1 \alpha, 25(\mathrm{OH}) 2$ vitamin D3: genomic and non-genomic 
mechanisms," Best Practice and Research: Clinical Endocrinology and Metabolism, vol. 25, no. 4, pp. 543-559, 2011.

[28] N. Rochel and F. Molnár, "Structural aspects of Vitamin D endocrinology," Molecular and Cellular Endocrinology, vol. 453, pp. 22-35, 2017.

[29] J. M. Zmuda, J. A. Cauley, and R. E. Ferrell, "Molecular epidemiology of vitamin D receptor gene variants," Epidemiologic Reviews, vol. 22, no. 2, pp. 203-217, 2000.

[30] E. M. Burns, P. Guroji, I. Ahmad et al., "Association of vitamin $\mathrm{D}$ receptor polymorphisms with the risk of nonmelanoma skin cancer in adults," JAMA Dermatology, vol. 153, no. 10, pp. 983-989, 2017.

[31] N. Denzer, T. Vogt, and J. Reichrath, "Vitamin D receptor (VDR) polymorphisms and skin cancer," Dermato-Endocrinology, pp. 205-210, 2011.

[32] K. Köstner, N. Denzer, M. Koreng et al., "Association of genetic variants of the vitamin $\mathrm{D}$ receptor (VDR) with cutaneous squamous cell carcinomas (SCC) and basal cell carcinomas (BCC): a pilot study in a German population," Anticancer Research, vol. 32, pp. 327-334, 2012.

[33] A. Lesiak, M. Norval, K. Wodz-Naskiewicz et al., "An enhanced risk of basal cell carcinoma is associated with particular polymorphisms in the VDR and MTHFR genes," Experimental Dermatology, vol. 20, no. 10, pp. 800-804, 2011.

[34] D. D. Bikle, Y. Jiang, T. Nguyen, Y. Oda, and C. Tu, "Disruption of vitamin $\mathrm{D}$ and calcium signaling in keratinocytes predisposes to skin cancer," Frontiers in Physiology, vol. 7, 2016.

[35] C. S. Hii and A. Ferrante, "The non-genomic actions of vitamin D," Nutrients, vol. 8, no. 3, 2016.

[36] K. M. Dixon, S. S. Deo, A. W. Norman et al., "In vivo relevance for photoprotection by the vitamin D rapid response pathway," Journal of Steroid Biochemistry and Molecular Biology, vol. 103, no. 3-5, pp. 451-456, 2007.

[37] J. E. Osborne and P. E. Hutchinson, "Vitamin D and systemic cancer: is this relevant to malignant melanoma?" British Association of Dermatologists, vol. 147, pp. 197-213, 2002.

[38] S. Kawal, T. Nikaido, Y. Aoki' et al., "Vitamin D analogues upregulate p21 and p27 during growth inhibition of pancreatic cancer cell lines," British Joumal of Cancer, no. 7, pp. 884-889, 1997.

[39] M. Liu, M.-H. Lee, M. Cohen, M. Bommakanti, and L. P. Freedman, "Transcriptional activation of the Cdk inhibit.or p21 B vitamin $\mathrm{D}_{3}$ leads to the induced differentiation of the myelomonocytic cell line $\mathrm{U}_{937}$," Genes \& Development, vol. 10, no. 2, pp. 142-153, 1996.

[40] L. Verlinden, A. Verstuyf, R. Convents, S. Marcelis, M. Camp, and R. Bouillon, "Action of 1,25(OH) $2 \mathrm{D}_{3}$ on the cell cycle genes, cyclin $\mathrm{D}_{1}, \mathrm{p} 21$ and p27 in MCF-7 cells," Molecular and Cellular Endocrinology, vol. 142, pp. 57-65, 1998.

[41] W.-M. Tong, E. K. Âllay, H. Hofer et al., "Growth regulation of human colon cancer cells by epidermal growth factor and 1,25-dihydroxyvitamin $\mathrm{D}_{3}$ is mediated by mutual modulation of receptor expression," European Journal of Cancer, vol. 34, no. 13, pp. 2119-2125, 1998 .

[42] K. Matsumoto, K. Hashimoto, Y. Nishida, M. Hashiro, and K. Yoshikawa, "Growth-inhibitory effects of 1,25-dihydroxyvitamin D3 on normal human keratinocytes cultured in serum-free medium," Biochemical and Biophysical Research Communications, vol. 166, no. 2, pp. 916-923, 1990.

[43] Y. Wu, J. D. Haugen, A. R. Zinsmeister, and R. Kumar, " $1 \alpha, 25$-dihydroxyvitamin $\mathrm{D}_{3}$ increases transforming growth factor and transforming growth factor receptor type I and II synthesis in human bone cells," Biochemical and Biophysical Research Communications, vol. 239, pp. 734-739, 1997.

[44] E. P. Amento, A. K. Bhalla, J. T. Kurnick et al., "1 alpha,25dihydroxyvitamin $\mathrm{D}_{3}$ induces maturation of the human monocyte cell line $U_{937}$, and, in association with a factor from human $\mathrm{T}$ lymphocytes, augments production of the monokine, mononuclear cell factor," Journal of Clinical Investigation, vol. 26, no. 1, p. 23, 1983.

[45] J. Reichrath, L. Rafi, M. Rech et al., "Analysis of the vitamin D system in cutaneous squamous cell carcinomas," Journal of Cutaneous Pathology, vol. 31, pp. 224-231, 2004.

[46] G. M. Zinser, J. P. Sundberg, and J. Welsh, "Vitamin $\mathrm{D}_{3}$ receptor ablation sensitizes skin to chemically induced tumorigenesis," Carcinogenesis, vol. 23, no. 12, pp. 2103-2109, 2002.

[47] K. K. Deeb, D. L. Trump, and C. S. Johnson, "Vitamin D signalling pathways in cancer: potential for anticancer therapeutics," Nature Reviews Cancer, vol. 7, no. 9, pp. 684-700, 2007.

[48] A. F. Gombart, N. Borregaard, and H. P. Koeffler, "Human cathelicidin antimicrobial peptide (CAMP) gene is a direct target of the vitamin $\mathrm{D}$ receptor and is strongly up-regulated in myeloid cells by 1,25 -dihydroxyvitamin $\mathrm{D}_{3}$," The FASEB Journal, vol. 19, no. 9, pp. 1067-1077, 2005.

[49] T.-T. Wang, F. P. Nestel, V. Bourdeau et al., "Cutting edge: 1,25-dihydroxyvitamin $\mathrm{D}_{3}$ is a direct inducer of antimicrobial peptide gene expression," The Journal of Immunology, vol. 173, no. 5, pp. 2909-2912, 2004.

[50] J.-M. Yuk, D.-M. Shin, H.-M. Lee et al., “Article vitamin $\mathrm{D}_{3}$ induces autophagy in human monocytes/macrophages via cathelicidin," Cell Host and Microbe, vol. 6, pp. 231-243, 2003.

[51] M. Li, P. Hener, Z. Zhang, S. Kato, D. Metzger, and P. Chambon, "Topical vitamin $\mathrm{D}_{3}$ and low-calcemic analogs inducethymic stromal lymphopoietin in mouse keratinocytesand trigger an atopic dermatitis," Proceedings of the National Academy of Sciences of the United States of America, vol. 103, no. 31, pp. 11736-11741, 2006.

[52] V. Soumelis, P. A. Reche, H. Kanzler et al., "Human epithelial cells trigger dendritic cell-mediated allergic inflammation by producing TSLP," Nature Immunology, vol. 3, no. 7, pp. 673-680, 2002.

[53] A. Pandey, K. Ozaki, H. Baumann et al., "Cloning of a receptor subunit required for signaling by thymic stromal lymphopoietin," Nature America, vol. 1, 2000.

[54] B. De, W. Malefyt, R. A. Kastelein et al., "Preferentially stimulates myeloid cells human thymic stromal lymphopoietin," Journal of Immunology, vol. 167, pp. 336-343, 2001.

[55] E. Sato-Deguchi, S. Imafuku, B. Chou, K. Ishii, K. Hiromatsu, and J. Nakayama, "Topical vitamin $\mathrm{D}_{3}$ analogues induce thymic stromal lymphopoietin and cathelicidin in psoriatic skin lesions," British Journal of Dermatology, vol. 167, no. 1, pp. 77-84, 2012.

[56] L. de Monte, M. Reni, E. Tassi et al., "Intratumor T helper type 2 cell infiltrate correlates with cancer-associated fibroblast thymic stromal lymphopoietin production and reduced survival in pancreatic cancer," Journal of Experimental Medicine, vol. 208, no. 3, pp. 469-478, 2011.

[57] B. E. Gress, C. Hesdorffer, W. J. Leonard et al., "Mediator of breast cancer progression thymic stromal lymphopoietin is a key," Journal of Immunology, vol. 186, pp. 5656-5662, 2011.

[58] A. Pedroza-Gonzalez, K. Xu, T. C. Wu et al., "Thymic stromal lymphopoietin fosters human breast tumor growth 
by promoting type 2 inflammation," Journal of Experimental Medicine, vol. 208, no. 3, pp. 479-490, 2011.

[59] M. di Piazza, C. S. Nowell, U. Koch, A. D. Durham, and F. Radtke, "Loss of cutaneous TSLP-dependent immune responses skews the balance of inflammation from tumor protective to tumor promoting," Cancer Cell, vol. 22, no. 4, pp. 479-493, 2012.

[60] E. L. Abel, J. M. Angel, K. Kiguchi, and J. DiGiovanni, "Multi-stage chemical carcinogenesis in mouse skin: fundamentals and applications," Nature Protocols, vol. 4, no. 9, pp. 1350-1362, 2009.

[61] J. V. Smit, S. Cox, W. A. M. Blokx, P. C. M. van de Kerhof, G. J. de Jongh, and E. M. G. J. de Jong, "Actinic keratosis in renal trans- plant recipients do not improve with calcipotriol cream and all-trans retinoic acid cream as monotherapies or in combination during a 6-week treatment period," British Journal of Dermatology, vol. 147, no. 4, pp. 816-818, 2002.

[62] A. Yen Moore, "Clinical applications for topical 5-fluorouracil in the treatment of dermatological disorders," Journal of Dermatological Treatment, vol. 20, no. 6, pp. 328-335, 2009.

[63] M. A. Weinstock, S. S. Thwin, J. A. Siegel et al., "Chemoprevention of basal and squamous cell carcinoma with a single course of fluorouracil, 5\%, cream: a randomized clinical trial," JAMA Dermatology, vol. 154, pp. 167-174, 2018.

[64] A. R. Rosenberg, M. Tabacchi, K. H. Ngo et al., "Skin cancer precursor immunotherapy for squamous cell carcinoma prevention," JCI Insight, vol. 4, no. 6, 2019.

[65] T. Dirschka, G. Gupta, G. Micali et al., "Real-world approach to actinic keratosis management: practical treatment algorithm for office-based dermatology," Journal of Dermatological Treatment, vol. 28, no. 5, pp. 431-442, 2017.

[66] S. M. Garland, "Imiquimod," Current Opinion in Infectious Diseases, vol. 16, no. 2, pp. 85-89, 2003.

[67] M. V. Dahl, "Imiquimod: a cytokine inducer," Journal of the American Academy of Dermatology, vol. 47, no. 4, 2002.

[68] A. K. Gupta, A. M. Cherman, and S. K. Tyring, "Viral and nonviral uses of imiquimod: a review," Journal of Cutaneous Medicine and Surgery, vol. 8, no. 5, pp. 338-352, 2004.

[69] S. Banerjee and D. Kaunelis, Imiquimod for the Treatment of Actinic Keratosis: A Review of Clinical Effectiveness and CostEffectiveness, Canadian Agency for Drugs and Technologies in Health, Ottaw, ON, USA, 2017.

[70] F. Flowers, "Imiquimod in the treatment of actinic keratoses and other intraepithelial neoplasms," International Journal of Dermatology, vol. 41, no. 1, pp. 12-15, 2002.

[71] D. Navi and A. Huntley, "Imiquimod 5 percent cream and the treatment of cutaneous malignancy," Dermatol Online J.vol. 10, no. 1, p. 4, 2004, https://pubmed.ncbi.nlm.nih.gov/ $15347486 /$.

[72] M. Sharma, G. Sharma, B. Singh, and O. P. Katare, "Actinic keratosis and imiquimod: a review of novel carriers and patents," Expert Opinion on Drug Delivery, vol. 16, no. 2, pp. 101-112, 2019.

[73] M. v. Heppt, T. Steeb, U. Leiter, and C. Berking, "Efficacy of photodynamic therapy combined with topical interventions for the treatment of actinic keratosis: a meta-analysis," Journal of the European Academy of Dermatology and Venereology, vol. 33, no. 5, pp. 863-873, 2019.

[74] G. M. Marrero and B. E. Katz, "The new fluor-hydroxy pulse peel a combination of 5 -fluorouracil and glycolic acid," Dermatologic Surgery, vol. 24, no. 9, pp. 973-978, 1998.
[75] B. M. Hantash, D. B. Stewart, Z. A. Cooper et al., "Facial resurfacing for nonmelanoma skin cancer prophylaxis," Archives of Dermatological, vol. 142, pp. 976-982, 2006.

[76] J. U. Ostertag, P. J. F. Quaedvlieg, S. van der Geer et al., “A clinical comparison and long-term follow-up of topical 5fluorouracil versus laser resurfacing in the treatment of widespread actinic keratoses," Lasers in Surgery and Medicine, vol. 38, no. 8, pp. 731-739, 2006.

[77] N. Krawtchenko, J. Roewert-Huber, M. Ulrich, I. Mann, W. Sterry, and E. Stockfleth, "A randomised study of topical $5 \%$ imiquimod vs. topical 5-fluorouracil vs. cryosurgery in immunocompetent patients with actinic keratoses: a comparison of clinical and histological outcomes including 1year follow-up," British Journal of Dermatology, vol. 157, 2007.

[78] E. Tanghetti and P. Werschler, "Comparison of 5\% 5-fluorouracil cream and $5 \%$ imiquimod cream in the management of actinic keratoses on the face and scalp," Journal of Drugs in Dermatology, vol. 6, no. 2, pp. 144-147, 2007.

[79] J. Jorizzo, J. Weiss, K. Furst, C. Vandepol, and S. F. Levy, "Effect of a 1-week treatment with $0.5 \%$ topical fluorouracil on occurrence of actinic keratosis after cryosurgery a randomized, vehicle-controlled clinical trial," Archives of Dermatological, vol. 140, no. 7, pp. 813-816, 2004.

[80] V. B. Morhenn, R. Fitzpatrick, S. Smith, D. Piacquadio, V. Morhenn, and D. Atkin, "Short incubation PDT versus 5FU in treating actinic keratoses," Journal of Drugs in Dermatology, vol. 2, no. 6, pp. 629-635, 2003.

[81] H. Pomerantz, D. Hogan, D. Eilers et al., "Long-term efficacy of topical fluorouracil cream, 5\%, for treating actinic keratosis: a randomized clinical trial," JAMA Dermatology, vol. 151, pp. 952-960, 2015.

[82] R. H. Rosen, A. K. Gupta, and S. K. Tyring, "Dual mechanism of action of ingenol mebutate gel for topical treatment of actinic keratoses: rapid lesion necrosis followed by lesionspecific immune response," Journal of the American Academy of Dermatology, vol. 66, no. 3, pp. 486-493, 2012.

[83] European Medicines Agency, EMA Suspends Picato as a Precaution while Review of Skin Cancer Risk Continues, European Medicines Agency, Amsterdam, Netherlands, 2020, https://www.ema.europa.eu/en/documents/press-release/emasuspends-picato-precaution-while-review-skin-cancer-riskcontinues_en.pdf.

[84] E. Stockfleth and M. Bastian, "Pharmacokinetic and pharmacodynamic evaluation of ingenol mebutate for the treatment of actinic keratosis," Expert Opinion on Drug Metabolism and Toxicology, vol. 14, no. 9, pp. 911-918, 2018.

[85] M. Lebwohl, N. Swanson, L. L. Anderson, A. Melgaard, Z. Xu, and B. Berman, "Ingenol mebutate gel for actinic keratosis," New England Journal of Medicine, vol. 366, no. 11, pp. 1010-1019, 2012.

[86] K. Kostovic, S. J. Gulin, Z. B. Mokos, and R. Ceovic, "Topical ingenol mebutate: a new treatment modality for multiple actinic keratoses and field cancerization," Anti-Cancer Agents in Medicinal Chemistry, vol. 17, no. 10, 2017.

[87] A. K. Gupta, M. Paquet, E. Villanueva, and W. Brintnell, "Interventions for actinic keratoses," Cochrane Database of Systematic Reviews, no. 12, p. 1-508, Article ID CD004415, 2012.

[88] B. Berman, "Safety and tolerability of ingenol mebutate in the treatment of actinic keratosis," Expert Opinion on Drug Safety, vol. 14, no. 12, pp. 1969-1978, 2015. 
[89] B. Berman and E. Stockfleth, "Field treatment of actinic keratosis with ingenol mebutate," Journal of Drugs in Dermatology, vol. 15, no. 5, pp. 535-542, 2016.

[90] B. Berman, M. S. Nestor, J. Newburger, H. Park, and N. Swenson, "Treatment of facial actinic keratoses with aminolevulinic acid photodynamic therapy (ALA-PDT) or ingenol mebutate $0.015 \%$ gel with and without prior treatment with ALA-PDT," Journal of Drugs in Dermatology, vol. 13, no. 11, pp. 1353-1356, 2014.

[91] M. Arisi, C. Zane, M. Polonioli et al., "Effects of MAL-PDT, ingenol mebutate and diclofenac plus hyaluronate gel monitored by high-frequency ultrasound and digital dermoscopy in actinic keratosis-a randomized trial," Journal of the European Academy of Dermatology and Venereology, vol. 34, no. 6, pp. 1225-1232, 2020.

[92] T. Gracia-Cazaña, A. J. G. Malinis, M. Almagro-Sánchez, D. P. Linares, and Y. Gilaberte, "Sequential daylight photodynamic therapy and ingenol mebutate versus 2 sessions of daylight photodynamic therapy for the treatment of actinic keratosis: an observational, prospective, comparative study," Photodiagnosis and Photodynamic Therapy, vol. 27, pp. 3438, 2019.

[93] T. Haque, K. M. Rahman, D. E. Thurston, J. Hadgraft, and M. E. Lane, "Topical therapies for skin cancer and actinic keratosis," European Journal of Pharmaceutical Sciences, vol. 77, pp. 279-289, 2015.

[94] R. Altman, B. Bosch, K. Brune, P. Patrignani, and C. Young, "Advances in NSAID development: evolution of diclofenac products using pharmaceutical technology," Drugs, vol. 75, no. 8, pp. 859-877, 2015.

[95] M. Ulrich, G. Pellacani, C. Ferrandiz, and J. T. Lear, "Evidence for field cancerisation treatment of actinic keratoses with topical diclofenac in hyaluronic acid," European Journal of Dermatology, vol. 24, no. 2, pp. 158-167, 2014.

[96] G. J. Thomas, P. Herranz, S. B. Cruz, and A. Parodi, "Treatment of actinic keratosis through inhibition of cyclooxygenase-2: potential mechanism of action of diclofenac sodium 3\% in hyaluronic acid 2.5\%," Dermatologic Therapy, vol. 32, no. 3, 2019.

[97] T. J. Gan, "Diclofenac: an update on its mechanism of action and safety profile," Current Medical Research and Opinion, vol. 26, no. 7, pp. 1715-1731, 2010.

[98] G. M. Martin and E. Stockfleth, "Diclofenac sodium 3\% gel for the management of actinic keratosis: $10+$ years of $\mathrm{cu}-$ mulative evidence of efficacy and safety," Journal of Drugs in Dermatology, vol. 11, no. 5, pp. 600-608, 2012.

[99] C. Nelson, D. Rigel, S. Smith, N. Swanson, and J. Wolf, "Phase IV, open-label assessment of the treatment of actinic keratosis with 3.0\% diclofenac sodium topical gel (Solaraze)," Journal of Drugs in Dermatology, vol. 3, no. 4, pp. 410-417, 2004.

[100] H.-C. Pommergaard, J. Burcharth, J. Rosenberg, and H. Raskov, "Combination chemoprevention with diclofenac, calcipotriol and difluoromethylornithine inhibits development of non-melanoma skin cancer in mice," Anticancer Research, vol. 33, no. 8, pp. 3033-3039, 2013.

[101] H. C. Pommergaard, J. Burcharth, J. Rosenberg, and H. Raskov, "Topical combination of diclofenac, calcipotriol, and difluoromethylornithine has beneficial effects comparable to 5-fluorouracil for the treatment of non-melanoma skin cancer in mice," Journal of Chemotherapy, vol. 26, no. 2, pp. 105-110, 2014.

[102] A. K. Bhatta, P. Wang, U. Keyal et al., "Therapeutic effect of Imiquimod enhanced ALA-PDT on cutaneous squamous cell carcinoma," Photodiagnosis and Photodynamic Therapy, vol. 23, pp. 273-280, 2018.

[103] M. Tampa, M. I. Sarbu, C. Matei et al., "Photodynamic therapy: a hot topic in dermato-oncology (review)," Oncology Letters, vol. 17, no. 5, pp. 4085-4093, 2019.

[104] M. J. Garland, C. M. Cassidy, D. Woolfson, and R. F. Donnelly, "Designing photosensitizers for photodynamic therapy: strategies, challenges and promising developments," Future Medicinal Chemistry, vol. 1, no. 4, pp. 667-691, 2009.

[105] A. E. O’Connor, W. M. Gallagher, and A. T. Byrne, "Porphyrin and nonporphyrin photosensitizers in oncology: preclinical and clinical advances in photodynamic therapy," Photochemistry and Photobiology, vol. 85, no. 5, pp. 1053 1074, 2009.

[106] M. O. Senge and M. W. Radomski, "Platelets, photosensitizers, and PDT," Photodiagnosis and Photodynamic Therapy, vol. 10, no. 1, pp. 1-16, 2013.

[107] S. Kwiatkowski, B. Knap, D. Przystupski et al., "Photodynamic therapy-mechanisms, photosensitizers and combinations," Biomedicine and Pharmacotherapy, vol. 106, pp. 1098-1107, 2018.

[108] A. Kim, J. Zhou, S. Samaddar et al., "An implantable ultrasonically-powered micro-light-source ( $\mu$ light) for photodynamic therapy," Scientific Reports, vol. 9, no. 1, 2019.

[109] H. Fukuda, A. Casas, and A. Batlle, "Aminolevulinic acid: from its unique biological function to its star role in photodynamic therapy," International Journal of Biochemistry and Cell Biology, vol. 37, no. 2, pp. 272-276, 2005.

[110] A. D. Garg and P. Agostinis, "ER stress, autophagy and immunogenic cell death in photodynamic therapy-induced anti-cancer immune responses," Photochemical and Photobiological Sciences, vol. 13, no. 3, pp. 474-487, 2014.

[111] C. Fu, B. H. Kuang, L. Qin, X. Y. Zeng, and B. C. Wang, "Efficacy and safety of photodynamic therapy with amino-5laevulinate nanoemulsion versus methyl-5-aminolaevulinate for actinic keratosis: a meta-analysis," Photodiagnosis and Photodynamic Therapy, vol. 27, pp. 408-414, 2019.

[112] T. Dirschka, P. Radny, R. Dominicus et al., "Long-term (6 and 12 months) follow-up of two prospective, randomized, controlled phase III trials of photodynamic therapy with BF200 ALA and methyl aminolaevulinate for the treatment of actinic keratosis," British Journal of Dermatology, vol. 168, no. 4, pp. 825-836, 2013.

[113] E. P. Tierney, M. J. Eide, G. Jacobsen, and D. Ozog, "Photodynamic therapy for actinic keratoses: survey of patient perceptions of treatment satisfaction and outcomes," Journal of Cosmetic and Laser Therapy, vol. 10, no. 2, pp. 81-86, 2008.

[114] S. Anand, C. Wilson, T. Hasan, and E. v. Maytin, "Vitamin $\mathrm{D}_{3}$ enhances the apoptotic response of epithelial tumors to aminolevulinate-based photodynamic therapy," Cancer Research, vol. 71, no. 18, pp. 6040-6050, 2011.

[115] K. R. Rollakanti, S. Anand, S. C. Davis, B. W. Pogue, and E. v. Maytin, "Noninvasive optical imaging of UV-induced squamous cell carcinoma in murine skin: studies of early tumor development and vitamin $\mathrm{D}$ enhancement of protoporphyrin IX production," Photochemistry and Photobiology, vol. 91, no. 6, pp. 1469-1478, 2015.

[116] K. Rollakanti, S. Anand, and E. v. Maytin, "Topical calcitriol prior to photodynamic therapy enhances treatment efficacy in non-melanoma skin cancer mouse models," Proceedings of the Society of Photo Optical Instrumentation, vol. 9308, Article ID 93080Q, 2015. 
[117] L. Torezan, B. Grinblat, M. Haedersdal, N. Valente, C. FestaNeto, and R. M. Szeimies, "A randomized split-scalp study comparing calcipotriol-assisted methyl aminolaevulinate photodynamic therapy (MAL-PDT) with conventional MAL-PDT for the treatment of actinic keratosis," British Journal of Dermatology, vol. 179, no. 4, pp. 829-835, 2018.

[118] R. Moreno, L. Nájera, M. Mascaraque, Á. Juarranz, S. González, and Y. Gilaberte, "Influence of serum vitamin $\mathrm{d}$ level in the response of actinic keratosis to photodynamic therapy with methylaminolevulinate," Journal of Clinical Medicine, vol. 9, no. 2, p. 398, 2020.

[119] G. N. Galimberti, "Calcipotriol as pretreatment prior to daylight-mediated photodynamic therapy in patients with actinic keratosis: a case series," Photodiagnosis and Photodynamic Therapy, vol. 21, pp. 172-175, 2018.

[120] D. F. Yang, J. H. Chen, C. P. Chiang et al., "Improve efficacy of topical ALA-PDT by calcipotriol through up-regulation of coproporphyrinogen oxidase," Photodiagnosis and Photodynamic Therapy, vol. 11, no. 3, pp. 331-341, 2014.

[121] I. Martincorena, A. Roshan, M. Gerstung et al., "High burden and pervasive positive selection of somatic mutations in normal human skin," Science, vol. 348, no. 6237, pp. 880-886, 2015.

[122] C. M. Perrett, J. M. Mcgregor, J. Warwick et al., “Treatment of post-transplant premalignant skin disease: a randomized intrapatient comparative study of 5-fluorouracil cream and topical photodynamic therapy," British Journal of Dermatology, vol. 156, no. 2, pp. 320-328, 2006.

[123] A. Befon, V. Tzanetakou, A. Panagiotopoulos, V. Chasapi, C. Antoniou, and A. J. Stratigos, "Imiquimod 3.75\% for fielddirected therapy of actinic keratosis: results of a prospective case-series study in Greece," International Journal of Dermatology, vol. 58, no. 9, pp. 1040-1044, 2019.

[124] J. Gras, "Ingenol mebutate: a new option for actinic keratosis treatment," Drugs of Today, vol. 49, no. 1, pp. 15-22, 2013.

[125] L. Anderson, G. J. Schmieder, W. P. Werschler et al., "Randomized, double-blind, double-dummy, vehicle-controlled study of ingenol mebutate gel $0.025 \%$ and $0.05 \%$ for actinic keratosis," Journal of the American Academy of Dermatology, vol. 60, no. 6, pp. 934-943, 2009.

[126] N. Neittaanmäki-Perttu, T. T. Karppinen, M. Grönroos, T. T. Tani, and E. Snellman, "Daylight photodynamic therapy for actinic keratoses: a randomized double-blinded nonsponsored prospective study comparing 5 -aminolaevulinic acid nanoemulsion (BF-200) with methyl-5-aminolaevulinate," British Journal of Dermatology, vol. 171, no. 5, pp. 1172-1180, 2014. 